\title{
IS PALM MID FRACTION A HEALTHIER CHOICE AS A COCOA BUTTER EQUIVALENT?
}

VOON, P T*; TOH, S W H**; NG, T K W*; LEE, V K M**; YONG, X S**; NG, Y T* and NESARETNAM, K+

\begin{abstract}
Palm mid fraction (PMF) is a fraction of palm oil rich in 1, 3-dipalmitoyl-2- oleoylglycerol (POP) triacylglycerol (TAG) that is obtained through re-fractionation of either palm olein or palm stearin. POP-, 1(3)-1, 3 distearoyl-2-oleoylglycerol (SOS)- and triolein (OOO)- type of fats have different melting characteristics that may affect postprandial lipid and glucose metabolism. We aimed to study the effects of palmitic, stearic or oleic acid situated at the sn-1 and sn-3 positions of edible fats on postprandial lipemia, glucose and insulin responses. A randomised, double-blind crossover ( $3 \times 3$ arms) orthogonal Latin-square design was used. A total of 36 healthy adults received three different test muffins, each containing $53 \mathrm{~g}$ of test fat from palm mid fraction (PMF as POP-rich fat), shea stearin (SS as SOS-rich fat) or high-oleic sunflower oil (HOSF as OOO-rich fat) plus a low-fat milkshake in random order separated by two weeks. No significant differences $(P>0.05)$ were observed between the three test meals for postprandial responses in plasma total cholesterol, Lp(a), glucose and insulin levels. However, plasma TAG levels were found significantly higher $(P<0.05)$ in PMF- and HOSF- subjects compared with SS- subjects after 90 min. Plasma C-peptide levels were found lower $(P<0.05)$ in the SS-subjects compared to the PMF- and HOSF- subjects. The results suggested that dietary fats containing palmitic (PMF) and oleic acid (HOSF) at the sn-1, 3 positions of the TAG backbone exert similar postprandial lipid and glucose responses compared with that of a stearic acid-rich sn-1,3 dietary fat (SS). In the food industry, there is demand for edible fats with different forms of TAG which can serve as a cocoa butter equivalent (CBE) i.e. as an important alternative for chocolates and other confectionary products.
\end{abstract}

Keywords: fatty acids, $s n-1$ and $s n-3$, postprandial lipemia, glucose, insulin.

Received: 16 July 2020; Accepted: 16 September 2020; Published online: 12 November 2020.

\section{INTRODUCTION}

The effects of edible fats on cholesterolemia have been well-documented ( $\mathrm{Hu}$ et al., 2001). Different

\footnotetext{
* Malaysian Palm Oil Board, 6 Persiaran Institusi, Bandar Baru Bangi, 43000 Kajang Selangor, Malaysia.

E-mail:vptee@mpob.gov.my

** International Medical University (IMU), Bukit Jalil, 57000 Kuala Lumpur, Malaysia.

$\ddagger$ Department of Allied Health Sciences, Faculty of Science, Universiti Tunku Abdul Rahman, Jalan Universiti, Bandar Barat, 31900 Kampar, Perak, Malaysia.

+ Jalan Kelab Golf, 40100 Shah Alam, Selangor, Malaysia.
}

types of saturated fatty acids (SFA) pose different effects on blood lipid. In fact, equations arising from human feeding trials have been formulated to predict blood cholesterol/lipid levels brought about by changes in dietary fat (Hegsted et al., 1965; Mensink et al., 2003).

Much of our knowledge on the impact of dietary fats on cardiovascular heart diseases is based on measurements of plasma lipid and lipoprotein profile in the fasting state, with the lowest low density lipoprotein cholesterol (LDL-c), LDL-c/ high density lipoprotein cholesterol (HDL-c) and triacylglycerol (TAG) being considered ideal. Lopez-Miranda and Marin (2010) highlighted the importance of dietary and physiological impacts on postprandial lipid metabolism. In this connection, 
postprandial hypertriglyceridemia is reported to increase the risk of type 2 diabetes mellitus, obesity, atherosclerosis, cardiovascular heart disease and stroke (Ortega et al., 2012).

The effects of stereospecific positioning of fatty acids in TAG molecules of dietary fats have been studied. Previous studies reported that palm oil has $41 \%$ palmitic acid (C16:0) with the majority of the fatty acid located at the $s n-1$ and $s n-3$ positions, but with only $3 \%-5 \%$ of its C16:0 at the $s n-2$ position (Karupaiah and Sundram, 2007; Kritchevsky, 2000). Chemical interesterification of palm oil is able to increase the amount of $\mathrm{C} 16: 0$ at the $s n-2$ position to $13.6 \%$ which results in a significant increase in atherogenicity of the interesterified fat (Karupaiah and Sundram, 2007; Kritchevsky, 2000).

In animal models, Storlien et al. (Storlien et al., 1991; Storlien et al., 1993) found that diets high in saturated, monounsaturated ( $\omega-9)$ and polyunsaturated ( $\omega-6)$ fatty acids induced severe insulin resistance, whereas long-chain $\omega$-3 fatty acids normalised the insulin action. However, published studies on the effects of different dietary fats on postprandial lipemia and insulin response in humans have not been consistent. Tholstrup et al. (2001) reported that the intake of long-chained saturated acids (palmitic acid and stearic acid) by 16 healthy men resulted in a relatively lower lipemic response than did intake of the unsaturated fatty acids. In a randomised, crossover study with 10 healthy men, Teng et al. (2011) found that palm olein (POP-rich fat) and olive oil (OOO-rich fat) caused a higher increase in postprandial lipemia than lard (SPO-rich fat). In contrast, Zampelas et al.'s postprandial study (Zampelas et al., 1994) and Galgani et al.'s extensive review (Galgani et al., 2008) reported that the positional distribution of fatty acids on dietary TAG or dietary fat quality does not influence postprandial lipemia nor insulin response.

The positional distribution of fatty acids in the TAG molecule varies greatly among fats and oils of different origins. In the food industry, there is a demand for edible fats with different forms of TAG which can serve as a CBE i.e. as an important alternative for chocolates and other confectionary products. Palm oil, illipe and shea are listed in the European Chocolate Directive 2000/36EEC as CBE (EU Commission, 2000). Besides, vegetable oils such as PMF, olive oil, mango fats, kokum and teaseed oil have also been used to prepare CBE. PMF is a fraction of palm oil rich in POP TAG that is obtained through re-fractionation of either palm olein or palm stearin. Therefore, it is important to find out if a CBE such as PMF has similar effects as SS on postprandial lipoprotein metabolism, glycemia and insulinemic response. This forms the research question as well as the justification for the present study reported.

\section{SUBJECTS AND METHODS}

\section{Subjects}

Thirty-six healthy adults (18 males and 18 females, aged between 25-50 years) were recruited to participate in this study. All volunteers underwent a health screening which included: a) an abbreviated medical/physical examination [blood pressure, weight, height, body mass index (BMI)], b) serum lipid profiling, c) plasma glucose determination, d) liver function tests [serum glutamic-oxaloacetic transaminase (SGOT) and serum glutamic-pyruvic transaminase (SGPT)] and e) kidney function test (serum creatinine). The inclusion criteria for this study were BMI 18.5-25.0 $\mathrm{kg} \mathrm{m}^{-2}$, systolic pressure $<140 \mathrm{mmHg}$, diastolic pressure $<90 \mathrm{mmHg}$, fasting total cholesterol (TC) $<6.2 \mathrm{mM} \mathrm{litre}^{-1}\left(<240 \mathrm{mg} \mathrm{dL}^{-1}\right)$, fasting TAG $<1.70$ mmol litre ${ }^{-1}\left(<150 \mathrm{mg} \mathrm{dL}^{-1}\right)$, fasting glucose $4.0-$ $7.0 \mathrm{mmol}$ litre $^{-1}$. Exclusion criteria for this study were individuals on cholesterol or blood glucose medication, substance abuse (e.g. alcohol, cigarette smoking), going overseas during period of study, having blood clotting problem and pregnant or lactating for women.

This study was approved by the IMU JointCommittee of Research and the Ethics Committee, International Medical University, Kuala Lumpur, Malaysia and this trial was registered at clinicaltrials.gov.my as NCT01428960.

\section{Study Design}

A randomised, double-blind crossover $(3 \times 3$ arms) orthogonal Latin-square design was used. Blood collections were conducted according to the study protocol at every $30 \mathrm{~min}$ interval. Each subject received three experimental test meals in a random order, two weeks apart, over a six-week period. Subjects were randomly allocated to one of following six treatment sequences: $\mathrm{ABC}, \mathrm{BCA}$, $\mathrm{CAB}, \mathrm{ACB}, \mathrm{CBA}$, or BAC, with PMF as A, SS as $B$ and HOSF as $C$. Each set of test meal contained a muffin and a glass milkshake. The test meal provided $875.6 \mathrm{kcal}, 16 \mathrm{~g}$ protein, $83 \mathrm{~g}$ carbohydrate and $53 \mathrm{~g}$ test fat.

\section{Sample Size Calculation}

Sample size was calculated based on $90 \%$ power at $P<0.017$ for cross-over within group comparison to detect a 0.5-SD unit change in the area under the curve (AUC) for plasma TAG concentrations, that provided a sample size of 36 subjects after allowing for $10 \%$ dropout. Secondary outcomes were changes in TC, Lp(a), glucose, insulin and C-peptide. The characteristics of the study participants are shown in Table 1. 


\section{Test Fats}

The three test fats were PMF (iodine value $=34.9$ ) and SS (iodine value = 34.1) which were obtained from Wilmar PGEO Edible Oils Sdn. Bhd. while HOSF was obtained from Intercontinental Specialty Fats Sdn Bhd, Selangor. PMF contained a similar proportion of SFA $(62.7 \%$ vs. $62.6 \%)$ and oleic acid $(33.7 \%$ vs. $33.0 \%$ ) when compared to SS but contained more palmitic acid $(57.1 \%$ vs. $1.8 \%)$ and less stearic acid $(5.0 \%$ vs. $60.8 \%)$. PMF and SS were blended with a small amount of sunflower oil (Mazola, Switzerland) so that linoleic acid (C18:2,w-6) was standardised across the diets at $7 \% \mathrm{kcal}$. The fatty acid composition of the test fats is shown in Table 2. The test fats were incorporated into muffins, labelled with a code, and stored frozen until being consumed.

The TAG composition of the test fats is illustrated in Table 3. PMF consists mainly of the TAG species 1, 3-dipalmitoyl-2- oleoylglycerol (POP) $(67.6 \%)$, while the majority of the TAG species in SS is 1(3)- 1, 3 distearoyl-2-oleoylglycerol (SOS) $(74.2 \%)$ with oleic acid in the $s n-2$ positions. The main TAG species of HOSF is triolein (OOO) $(66.5 \%)$.

The three test fats consist of approximately equal oleic acid $(\mathrm{C} 18: 1)$ at the $s n-2$ position [(PMF $=72 \%, \mathrm{SS}=80 \%$, HOSF $=88 \%)]$. Differential scanning calorimetry showed that PMF shows a single sharp melting peak at approximately $31.3^{\circ} \mathrm{C}$, whereas SS shows a higher melting point at approximately $38.0^{\circ} \mathrm{C}$. HOSF shows a melting point at approximately $0.14^{\circ} \mathrm{C}$.

\section{Postprandial Protocol}

Subjects were asked to avoid consuming foods high in fat as well as not to participate in strenous exercise the day preceding each test meal and to fast overnight beginning at $2200 \mathrm{hr}$. A low-fat meal (500$700 \mathrm{kcal}$ containing, $10 \mathrm{~g}$ fat) was provided to the subjects as their evening meal. The subjects were requested to consume the low-fat meal before 2200 hr and fast overnight.

On the morning of the postprandial test, participants attended the Nutrition Group Clinic between $0800 \mathrm{hr}$ and $1000 \mathrm{hr}$ when a 22G" Vasofix ${ }^{\circledR}$ Brannule (Cat No. 426 8091B, B. Braun, Germany) was inserted into the antecubital vein of the forearm and held in place with a Connecta (Cat No. 394601, Becton - Dickinson, Sweden). Blood was collected by syringe and dispensed into appropriate uncapped blood collection containers. Samples for TAG, TC, $\mathrm{Lp}(\mathrm{a})$, insulin and C-peptide analysis were collected using serum vacutainer tubes. The samples collected were allowed to clot at room temperature before centrifugation. Samples for plasma glucose was collected using fluoride containing tube. The serum and plasma were aliquoted accordingly and stored in $-80^{\circ} \mathrm{C}$ freezer prior to analyses.

The subjects were given $10 \mathrm{~min}$ to consume a set of test meal. Venous blood samples were collected every $30 \mathrm{~min}$ for $4 \mathrm{hr}$ after the test meal. Blood collection was performed by registered staff nurse supervised by medical officer or family physician using antiseptic technique. Drinking water was provided to the subjects over $4 \mathrm{hr}$. At the end of $4 \mathrm{hr}$, the subjects were provided with an ad-libitum lunch.

TABLE 1. BASELINE CHARACTERISTICS OF THE STUDY PARTICIPANTS

\begin{tabular}{|c|c|c|c|}
\hline \multirow{2}{*}{ Variable } & \multicolumn{3}{|c|}{ Participants } \\
\hline & Women $(n=18)$ & Men $(n=18)$ & All $(n=36)$ \\
\hline Age (yr) & $23.0 \pm 1.1$ & $23.0 \pm 1.9$ & $23.3 \pm 1.5$ \\
\hline Weight (kg) & $52.0 \pm 5.6$ & $63.1 \pm 7.6$ & $57.5 \pm 8.7$ \\
\hline Height (cm) & $160.0 \pm 4.2$ & $172.0 \pm 5.7$ & $166.0 \pm 8.0$ \\
\hline BMI $\left(\mathrm{kg} \mathrm{m}^{-2}\right)$ & $20.3 \pm 1.6$ & $21.3 \pm 2.0$ & $20.8 \pm 1.8$ \\
\hline Systolic blood pressure (mmHg) & $111.0 \pm 6.1$ & $122.0 \pm 10.0$ & $116.0 \pm 9.9$ \\
\hline Diastolic blood pressure (mmHg) & $73.0 \pm 5.0$ & $75.0 \pm 7.6$ & $74.0 \pm 6.4$ \\
\hline Total cholesterol (mmol litre ${ }^{-1}$ ) & $4.9 \pm 0.7$ & $4.4 \pm 0.8$ & $4.7 \pm 0.8$ \\
\hline HDL-c (mmol litre $\left.{ }^{-1}\right)$ & $1.7 \pm 0.3$ & $1.4 \pm 0.3$ & $1.5 \pm 0.3$ \\
\hline LDL-c (mmol litre $\left.{ }^{-1}\right)$ & $2.9 \pm 0.6$ & $2.7 \pm 0.7$ & $2.8 \pm 0.6$ \\
\hline TAG (mmol litre $\left.{ }^{-1}\right)$ & $0.7 \pm 0.3$ & $0.7 \pm 0.4$ & $0.7 \pm 0.3$ \\
\hline Fasting glucose (mmol litre $\left.{ }^{-1}\right)$ & $4.6 \pm 0.6$ & $4.7 \pm 0.3$ & $4.6 \pm 0.3$ \\
\hline
\end{tabular}

Note: All values are mean \pm SD.

BMI - body mass index; HDL-c - high-density lipoprotein cholesterol; LDL-c - low-density lipoprotein cholesterol; TAG - triacylglycerol; PMF - palm mid fraction; SS - shea stearin; HOSF - high-oleic sunflower oil. 
TABLE 2. FATTY ACID COMPOSITIONS OF THE TEST FATS

\begin{tabular}{lccc}
\hline & Fatty acids & \multicolumn{2}{c}{ Mol $\%$} \\
\cline { 2 - 4 } & PMF & SS & HOSF \\
\hline C14:0 & 0.61 & ND & ND \\
C16:0 & 52.85 & 2.40 & 4.44 \\
C18:0 & 4.87 & 57.20 & 2.41 \\
C18:1 & 33.73 & 32.29 & 85.58 \\
C18:2 & 7.93 & 7.63 & 7.56 \\
Others & 0.01 & 0.48 & 0.01 \\
SFA & 58.33 & 59.60 & 6.85 \\
MUFA & 33.73 & 32.29 & 85.58 \\
PUFA & 7.93 & 7.63 & 7.56 \\
\hline
\end{tabular}

Note: ND - not detected; SFA - saturated fatty acids; MUFA - monounsaturated fatty acids; PUFA - polyunsaturated fatty acids; PMF - palm mid fraction; SS - shea stearin; HOSF - high-oleic sunflower oil.

TABLE 3. TAG COMPOSITION OF THE TEST FATS

\begin{tabular}{lccc}
\hline & TAG & Mol $\%$ & HOSF \\
\cline { 2 - 4 } PLL & PMF & SS & ND \\
MLP & 0.1 & ND & ND \\
OLO & 0.2 & ND & 6.3 \\
PLO & 0.2 & ND & 1.1 \\
PLP & 1 & ND & 0.2 \\
OOO & 8.7 & 0.3 & 66.5 \\
POO & 0.9 & 0.6 & 9 \\
POP & 3.1 & 1 & 0.5 \\
PPP & 67.6 & 3.2 & ND \\
SOO & 2.5 & 7.1 & 5.9 \\
POS & 0.3 & 7.4 & 0.4 \\
PPS & 13.3 & 0.2 & ND \\
SOS & 0.4 & 74.2 & ND \\
Others & 1.5 & 5.9 & 10.1 \\
Slip melting point $\left({ }^{\circ} \mathrm{C}\right)$ & ND & 37.9 & $<1.0$ \\
\hline
\end{tabular}

Note: ND - not detected; TAG - triacylglycerol; L - linoleic acid (18:2n-6); M - myristic acid (14:0); O - oleic acid (18:1n-9); P - palmitic acid (16:0); S - stearic acid (18:0); PMF - palm mid fraction; SS - shea stearin; HOSF - high-oleic sunflower oil.

\section{Analytical Methods}

Serum TAG, TC, Lp(a) and plasma glucose were analysed using enzymatic colourimetric assays with a Hitachi 902 autoanalyser (Roche Diagnostics $\mathrm{GmbH})$. The fatty acid composition of test fats was measured using gas-liquid chromatography on an SP-2560 column (100 m x $0.23 \mathrm{~mm} \times 0.2 \mathrm{~mm}$; Agilent Technologies) with a flame ionisation detector on an autosystem (Perkin Elmer). The carrier gas (helium) pressure and injector temperature were set to $40 \mathrm{psi}$ and $250^{\circ} \mathrm{C}$, respectively. The oven temperature was set isothermal at $240^{\circ} \mathrm{C}$ for $42 \mathrm{~min}$. Hydrogen and compressed air were used for ignition. A fatty acid methyl esters mixture (Sigma-Aldrich, Australia) was used as the external standard.

TAG composition of the test fats was determined by reversed-phase High Performance Liquid Chromatography (HPLC) system. The method of analysis was modified from AOCS Official Method Ce 5c-93 (AOCS Official Method 1995). Slip-melting point was determined according to MPOB Test Method (MPOB, 2004). 
Meanwhile, both C-peptide and insulin samples were analysed using (Elecsys module) immunoassay analysers. Although the 'Homeostatic Model Assessment' (HOMA = fasting insulin concentration $\times$ fasting glucose concentration /22.5) (Matthews et al., 1985) and the quantitative insulin sensitivity check index [QUICKI= the inverse of the sum of the logarithms of the fasting insulin and fasting glucose, i.e. $[1 /$ ( $\log$ (fasting insulin $)+\log$ (fasting glucose) (Katz et al., 2000) are normally used for fasting blood samples, these indices of insulin resistance were calculated for the $4 \mathrm{hr}$ time-point following the three test meals, which may be considered as the early fasting phase in the study.

\section{Statistical Analyses}

Repeated measure analysis of variance (ANOVA) with Bonferroni post hoc analysis was conducted using GraphPad Prism version 5 (GraphPad Software, La Jolla, CA 9203, USA) and PASW Statistics 18 to assess the significant difference between diets. The normal distribution of data was assessed using Shapiro-Wilk's normality test and logarithmic transformations were used when necessary. Data are expressed as mean with $95 \% \mathrm{CI}$.

\section{RESULTS}

Table 4 and Figure 1 show the postprandial changes in serum TAG and following the three test meals. The meal $\times$ time interaction $(P=0.000)$ for the change in postprandial TAG indicated differences between test meals; plasma TAG increased more rapidly following PMF and HOSF compared with that of a SS test meal.

There were significant differences in serum TAG levels between the test diets at $120 \mathrm{~min}$ and $180 \mathrm{~min}$. Postprandial changes in TAG between the HOSF and SS showed a significant meal $\times$ time interaction ( $P=0.0041)$ at $120 \mathrm{~min}$; the difference was $0.24(95 \%$ CI, 0.064, 0.41). Meanwhile, comparison of PMF and HOSF with the SS meal showed a significant meal $\times$ time interaction $(P=0.0075)$ at $180 \mathrm{~min}$ in which the differences between HOSF and PMF with the SS meal in the change of TAG were $0.26(95 \%$ CI, $0.052,0.47)$ and $-0.21(95 \% \mathrm{CI},-0.42,-0.00076)$ respectively.

The differences between HOSF and PMF with the SS meal in the change of TAG at 150 min were 0.25 (95\% CI, 0.12, 0.37) and $-0.22(95 \% \mathrm{CI},-0.35$, -0.094) respectively, at $180 \mathrm{~min} 0.23$ (95\% CI, 0.096, $0.36)$ and $-0.17(95 \% \mathrm{CI},-0.30,-0.040)$ and at 210 $\min 0.22(95 \% \mathrm{CI}, 0.084,0.36)$ and $-0.20(95 \% \mathrm{CI}$, $-0.34,-0.060)$. Moreover, the release of C-peptide following PMF test meals was significantly different $(P=0.0028)$ from SS at $240 \mathrm{~min}$ time-point i.e. -0.29 (95\% CI, $-0.48,-0.090)$.

TAG responses did not differ significantly between the three types of test meal given at $60 \mathrm{~min}$ and $240 \mathrm{~min}$. Moreover, there were no significant differences $(P>0.05)$ between meals and times in TC (Table 5), Lp(a) (Table 6), glucose and insulin.

Figure 2 illustrates the postprandial changes in serum C-peptide following the test meals. The meal $\mathrm{x}$ time interaction $(P=0.000)$ for the change in postprandial $C$-peptide indicated differences between test meals. The total amount of C-peptide released by pancreatic $\beta$-cells following PMF and HOSF test meals were higher as compared to the SS test meal. Comparison of the postprandial changes between the HOSF and SS showed a significant difference at $120 \mathrm{~min}(P<0.048)$; the difference was 0.15 ( $95 \%$ CI, $0.0021,0.31)$. Meanwhile, comparison of PMF and HOSF with the SS meal showed a significant meal $\times$ time interaction difference at 150 $\min (P<0.0001)$, at $180 \mathrm{~min}(P=0.0002)$ and at 210 $\min (P=0.003)$.

TABLE 4. POSTPRANDIAL CHANGES IN TAG FOLLOWING THE THREE TEST MEALS

\begin{tabular}{cccc}
\hline \multirow{2}{*}{ Time (min) } & \multicolumn{3}{c}{ Changes in TAG of test meals $\left(\mathbf{m m o l ~ l i t r e}^{-1}\right)$} \\
\cline { 2 - 4 } & HOSF & SS & PMF \\
\hline 0 & $0.77(0.66,0.89)$ & $0.86(0.75,0.97)$ & $0.82(0.69,0.94)$ \\
60 & $0.83(0.69,0.95)$ & $0.83(0.72,0.94)$ & $0.84(0.70,0.97)$ \\
120 & $1.19(0.99,1.38)^{\mathrm{a}}$ & $0.95(0.81,1.1)^{\mathrm{b}}$ & $1.12(0.95,1.28)^{\mathrm{a}}$ \\
180 & $1.47(1.22,1.68)^{\mathrm{a}}$ & $1.2(1.01,1.39)^{\mathrm{b}}$ & $1.41(1.19,1.62)^{\mathrm{a}}$ \\
240 & $1.46(1.21,1.68)$ & $1.37(1.16,1.56)$ & $1.49(1.26,1.69)$ \\
\hline
\end{tabular}

Note: Values are geometric means; 95\% CIs in parentheses; $(n=36 ; 18$ men, 18 women) for all treatments. Values were log-transformed, analysed by repeated-measures analysis of variance (ANOVA) and showed a diet $\times$ time interaction $(P=0.000)$; the meal $\times$ gender, time $\times$ gender and meal $\times$ gender $x$ time interaction were not significant. Different superscript letters in the same row indicate that values showed statistically significant differences $(P<0.05$, Bonferroni multiple comparison test) between corresponding columns.

TAG - triacylglycerol; PMF - palm mid fraction; SS - shea stearin; HOSF - high-oleic sunflower oil. 
TABLE 5. POSTPRANDIAL CHANGES IN TC FOLLOWING THE THREE TEST MEAL

\begin{tabular}{cccc}
\hline \multirow{2}{*}{ Time (min) } & \multicolumn{3}{c}{ Changes in TC of test meals $\left(\mathrm{mmol} \mathrm{litre}^{-1}\right)$} \\
\cline { 2 - 4 } & HOSF & SS & HOSF \\
\hline 0 & $5.00(4.72,5.28)$ & $4.90(4.64,5.17)$ & $4.97(4.73,5.21)$ \\
60 & $4.88(4.59,5.17)$ & $4.69(4.42,4.95)$ & $4.72(4.50,4.94)$ \\
120 & $4.86(4.58,5.14)$ & $4.75(4.46,5.04)$ & $4.74(4.53,4.96)$ \\
180 & $4.85(4.58,5.12)$ & $4.74(4.47,5.00)$ & $4.74(4.52,4.96)$ \\
240 & $4.92(4.65,5.19)$ & $4.77(4.52,5.03)$ & $4.79(4.58,5.01)$ \\
\hline
\end{tabular}

Note: Values are means; $95 \%$ CIs in parentheses; $(n=36 ; 18$ men, 18 women) for all treatments. Values were analysed by repeated-measures analysis of variance (ANOVA) and diet $x$ time, the meal $x$ gender, time $\mathrm{x}$ gender and meal $\mathrm{x}$ gender $\mathrm{x}$ time interaction were not significant $(P>0.05)$.

TC - total cholesterol; PMF - palm mid fraction; SS - shea stearin; HOSF - high-oleic sunflower oil.

TABLE 6. POSTPRANDIAL CHANGES IN LP(A) FOLLOWING THE THREE TEST MEALS

\begin{tabular}{cccc}
\hline \multirow{2}{*}{ Time (min) } & \multicolumn{3}{c}{ Changes in Lp(a) of test meals $\left(\mathrm{mg} \mathrm{dL}^{-1}\right)$} \\
\cline { 2 - 4 } & HOSF & SS & HOSF \\
\hline 0 & $31.05(25.46,37.87)$ & $29.99(24.15,37.25)$ & $28.15(22.67,34.96)$ \\
60 & $29.95(24.35,36.83)$ & $28.56(23.01,35.47)$ & $29.23(23.76,35.96)$ \\
120 & $33.69(27.78,40.86)$ & $31.71(25.61,39.27)$ & $33.41(27.50,40.60)$ \\
180 & $36.44(30.28,43.84)$ & $35.24(28.67,43.32)$ & $36.56(30.10,44.42)$ \\
240 & $37.65(31.56,44.91)$ & $38.70(31.65,47.32)$ & $38.15(31.56,46.11)$ \\
\hline
\end{tabular}

Note: Values are geometric means; 95\% CIs in parentheses; $(n=36 ; 18$ men, 18 women) for all treatments. Values were log-transformed, analysed by repeated-measures analysis of variance (ANOVA) and diet $x$ time, the meal $x$ gender, time $x$ gender and meal $x$ gender $x$ time interaction were not significant $(P>0.05)$.

Lp(a) - lipoprotein(a); PMF - palm mid fraction; SS - shea stearin; HOSF - high-oleic sunflower oil.

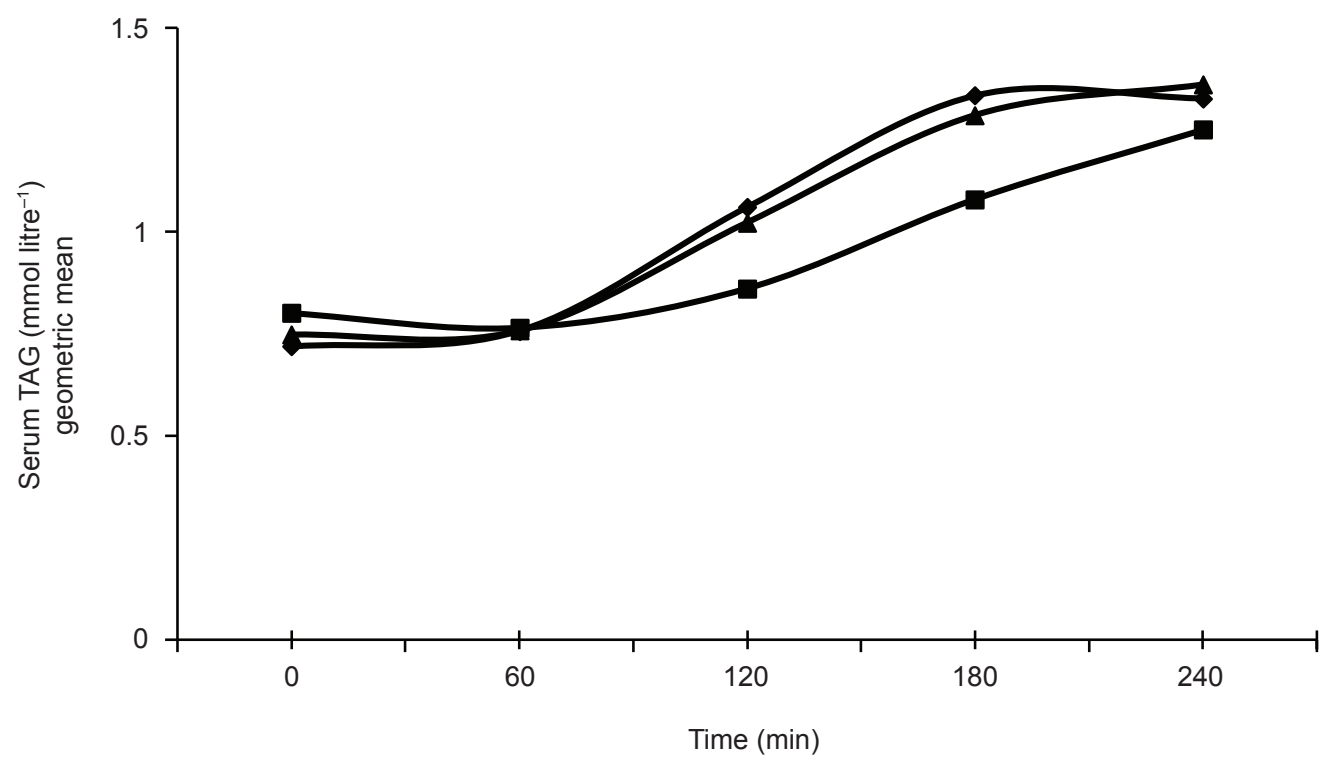

Note: PMF - palm mid fraction; SS - shea stearin; HOSF - high-oleic sunflower oil, TAG - triacylglycerol.

Figure 1. Postprandial concentrations of serum TAG geometric mean ( $n=36 ; 18$ men, 18 women) following three test meals containing $53 \mathrm{~g}$ test fat from $\operatorname{HOSF}(\downarrow), S S(\boldsymbol{\square})$, and PMF $(\boldsymbol{\Lambda})$. Deviations from postprandial values were analysed by repeated measures analysis of variance (ANOVA); meal $\times$ time interaction $P=0.000$. Comparisons between meals were adjusted by using a Bonferroni multiple-comparison test. 


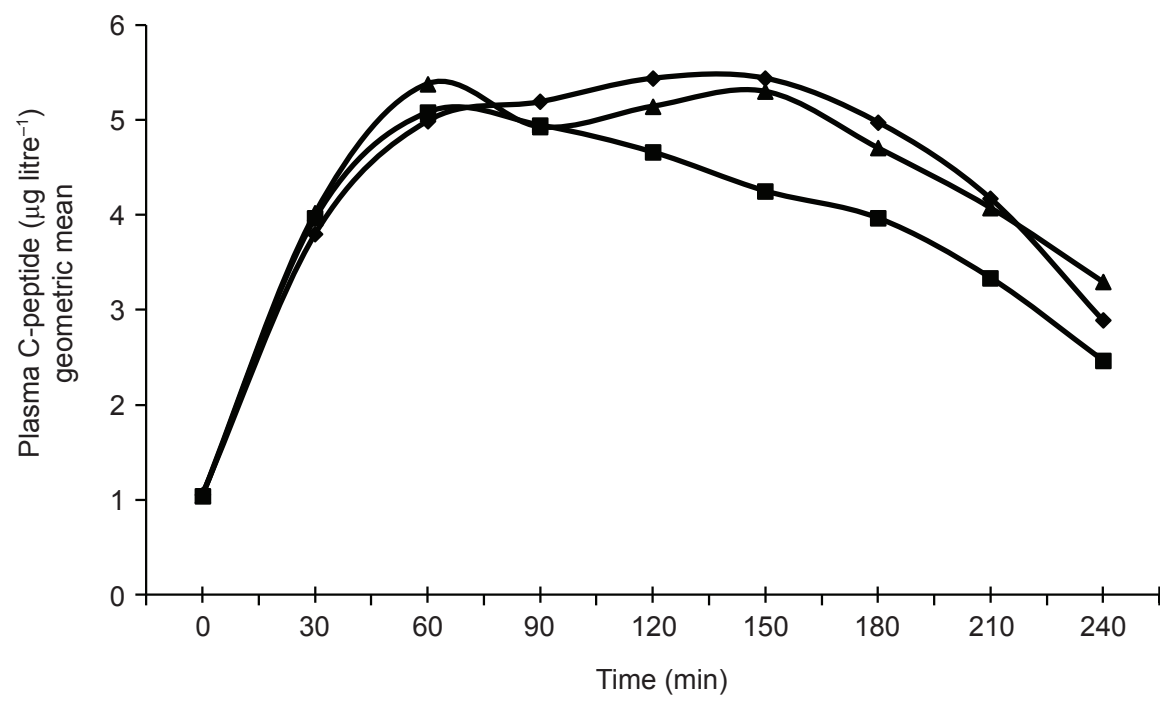

Note: PMF - palm mid fraction; SS - shea stearin; HOSF - high-oleic sunflower oil.

Figure 2. Postprandial concentrations of plasma C-peptide geometric mean $(n=36 ; 18$ men, 18 women) following three test meals containing $53 \mathrm{~g}$ test fat from HOSF ( ), SS (घ), and PMF $(\mathbf{\Lambda})$. Deviations from postprandial values were analysed by repeated measures analysis of variance (ANOVA); meal $\times$ time interaction $P=0.000$. Comparisons between meals were adjusted by using a Bonferroni multiple-comparison test.

\section{DISCUSSION}

PMF and SS are widely used as CBE due to their desirable mouth-feel effects arising from their respective melting point of $31.3^{\circ} \mathrm{C}$ and $38.0^{\circ} \mathrm{C}$ (Lipp and Anklam, 1998). PMF displays a steep melting profile, with a narrow melting interval around $35.0^{\circ} \mathrm{C}$ which makes it an important component of confectionary fats, being the source of palmitic acid-rich TAG in the formulation of CBE (Salas et al., 2009).

To date, there are lack of human studies comparing both PMF and SS as test fats in diets. However, there are several reports of SS being used in postprandial test meals (Berry and Sanders, 2005; Sanders and Berry, 2005). In the present study, the amounts of oleic acid at $s n-2$ position in all the three types of TAG molecules of PMF, SS and HOSF were approximately equal, linoleic acid content was standardised across diets, and the major difference between the test fats are the fatty acid type in the $s n-1$ and $s n-3$ positions, namely palmitic acid in the case of PMF (POP), oleic acid for HOSF (OOO) and stearic acid in the case of SS (SOS). In this study, the PMF and HOSF test fats exerted a similar postprandial TAG profile, which not only suggests that palmitic acid and oleic acid have comparable postprandial triglyceridemic effects but also the two types of fatty acids were similarly absorbed. The SS- (SOS) meal however, resulted in a lower postprandial TAG response compared to HOSF(OOO) and PMF- (POP) meal.

The lower postprandial level of lipemia following SS in the present study is in agreement with results reported by Sanders and Berry (2005) that non-randomised SS resulted in decreased lipemia as compared to a test meal containing $50 \mathrm{~g}$ HOSF. Sanders et al. (Sanders et al., 2000) suggested that the lower postprandial lipemic effect of a stearic acid-rich SS meal was due to a slower absorption rate and led to the formation of smaller lipoprotein particles compared to an oleic acid-rich HOSF meal with a faster absorption rate and larger chylomicrons formation. However, the mechanism involved warrant further investigations. Evidently, differences in the physical characteristics of fats and stereospecific structure of TAG molecules influence the metabolism of lipids and the level of postprandial lipemia. In this connection, Berry et al. (2007) proposed that SS contains a higher proportion of solid fat at $37^{\circ} \mathrm{C}$ compared with HOSF and PMF and this may cause SS to be emulsified less readily and is less absorbed due to its higher melting point, resulting in a slower increase in serum TAG levels. This would suggest that SS might be cleared from the circulation faster than HOSF and PMF and resulted in a more prolonged postprandial lipemia which explains our results obtained.

Meanwhile, there were no significant differences in postprandial serum TC and Lp(a) levels after ingestion of the three test meals. Our present findings for TC levels are in accordance to the results obtained by Forsythe et al. (2007) who reported that that a $s n-1+s n-3$ palmitic acid-rich fat such as palm oil is non-cholesterolemic. In contrast, Tholstrup and Samman (2004) reported that postprandial $\mathrm{Lp}(\mathrm{a})$ is affected differently by specific individual dietary fatty acids in healthy young men, while Sanders et al. (2000) found that shorter-chain fatty acids will clear $L \mathrm{p}(\mathrm{a})$ at a faster rate after a postmeal study with high and normal fat loads. 
TABLE 7. PLASMA GLUCOSE, INSULIN, HOMA AND QUICKI VALUES FOLLOWING THE THREE TEST MEALS AT 240 MIN

\begin{tabular}{lccc}
\hline Plasma index & HOSF & SS & PMF \\
\hline HOMA & $4.43(2.90,5.97)$ & $4.68(2.91,6.44)$ & $7.27(4.85,9.69)$ \\
QUICKI & $0.34(0.32,0.36)$ & $0.34(0.32,0.35)$ & $0.32(0.30,0.34)$ \\
Glucose & $5.15(4.93,5.37)$ & $5.27(4.98,5.57)$ & $5.54(5.25,5.84)$ \\
Insulin & $18.71(12.34,25.07)$ & $18.96(12.03,25.90)$ & $28.54(19.07,38.00)$ \\
\hline
\end{tabular}

Note: Values are means; $95 \%$ CIs in parentheses $(n=36 ; 18$ men, 18 women) for all treatments. Values were log-transformed, analysed by repeated-measures analysis of variance (ANOVA); HOMA, diet $\times$ time interaction $(P>0.05)$; QUICKI, diet $\times$ time interaction $(P>0.05)$. HOMA - Homeostatic Model Assessment; QUICKI - Quantitative Insulin Sensitivity Check Index; PMF - palm mid fraction; SS - shea stearin; HOSF - high-oleic sunflower oil.

C-peptide and insulin are initially synthesised in the same polypeptide. The C-peptide component is later cleaved off leaving the A- and B-chains which form insulin. C-peptide concentrations specifically reflect $\beta$-cell function because $C$-peptide is secreted in equimolar amounts with insulin and is not removed in the first pass through the liver (Hills and Brunskill, 2009; Kim et al., 2012). Moreover, C-peptide is a more stable biomarker of insulin secretion than is the direct measurement of plasma insulin because C-peptide has a substantially longer half-life than insulin (Nimptsch et al., 2011). In the present postprandial study, C-peptide responses peaked in the three test-fat groups about $60 \mathrm{~min}$ after the test meals were consumed and its serum concentrations decreased significantly $(P<0.05)$ to around $2.8 \mu \mathrm{g}$ litre $^{-1}$ towards the end of the $4 \mathrm{hr}$ study. There were significant differences in C-peptide responses among the three groups. Overall, postprandial C-peptide concentrations were lower $(P<0.05)$ after a SS-meal compared to the HOSF and PMF-meals. This suggests that C-peptide concentrations following the SS-meal were cleared faster as compared to the HOSF- and PMF-meals.

Postprandial glucose and insulin concentrations did not differ following the meals high in palmitic acid-(POP) and rich in stearic acid- (SOS) compared to HOSF which was rich in oleic acid- (OOO). The comparable postprandial insulin concentration across the three test-fat groups also strengthens our suggestion that $\mathrm{C}$-peptide concentrations were cleared at a faster rate in the SS-meal group. Our results are consistent with the findings of Lopez et al. (2011) which showed no significant difference in postprandial glucose response in subjects who consumed monounsaturated and saturated fats. In agreement with the previous study of Teng et al. (2011), a single high fat load may not affect the changes in glucose and insulin levels, as the meal $x$ time interaction was not significant indicating that the peak insulin concentration was reached at the same time across meals, which was at $30 \mathrm{~min}$. Our results suggest that POP-, SOS- and OOO- type of fats did not affect postprandial glucose and insulin responses. The HOMA and QUICKI (Table 7) indices at the $4 \mathrm{hr}$ time-point (early fasting phase) were also comparable across the three test-fat groups.

\section{CONCLUSION}

The preponderance of either palmitic (16:0), stearic (18:0) or oleic acid (18:1) of the three test fats with different physical characteristics used in the present acute study did not induce any significant differences in postprandial $L p(a)$, glucose or insulin concentrations. Our findings, however, demonstrated that PMF (POP) and HOSF (OOO) fats induced higher TAG and C-peptide postprandial concentrations compared with the SS (SOS) fat.

\section{ACKNOWLEDGEMENT}

We thank all the participants in the study, the medical team which played a key role in blood sample collection and Wilmar PGEO Edible Oils Sdn Bhd and Intercontinental Specialty Fats Sdn Bhd for providing the test fats used. We also thank the Director-General of MPOB for permission to publish the data.

\section{REFERENCES}

Berry, S E; Miller, G J and Sanders, T A (2007). The solid fat content of stearic acid-rich fats determines their postprandial effects. Am. J. Clin. Nutr., 85(6): 1486-1494.

Berry, S E and Sanders, T A (2005). Influence of triacylglycerol structure of stearic acid-rich fats on postprandial lipaemia. Proc. Nutr. Soc., 64(2): 205212. 
EU Commission (2000). Directive 2000/36/EC of the European Parliament and of the Council of 23 June 2000 relating to cocoa and chocolate products intended for human consumption. Official J. European Communities EG 197: 19.

Forsythe, C E; French, M A; Goh, Y K and Clandinin, M T (2007). Cholesterolaemic influence of palmitic acid in the $s n-1,3 \mathrm{v}$. the $s n-2$ position with high or low dietary linoleic acid in healthy young men. $B r$. J. Nutr., 98(2): 337-344.

Galgani, J E; Uauy, R D; Aguirre, C A and Diaz, E $\mathrm{O}$ (2008). Effect of the dietary fat quality on insulin sensitivity. Br. J. Nutr., 100(3): 471-479.

Hegsted, D M; Mcgandy, R B; Myers, M L and Stare, F J (1965). Quantitative effects of dietary fat on serum cholesterol in man. Am. J. Clin. Nutr., 17(5): 281-295.

Hills, C E and Brunskill, N J (2009). Cellular and physiological effects of C-peptide. Clin. Sci. (Lond) 116(7): 565-574.

Hu, F B; Manson, J E and Willett, W C (2001). Types of dietary fat and risk of coronary heart disease: A critical review. J. Am. Coll. Nutr., 20(1): 5-19.

Karupaiah, T and Sundram, K (2007). Effects of stereospecific positioning of fatty acids in triacylglycerol structures in native and randomized fats: A review of their nutritional implications. Nutrition and Metabolism, 4: 16-16.

Katz, A; Nambi, S S; Mather, K; Baron, A D; Follmann, D A; Sullivan, G and Quon, M J (2000). Quantitative insulin sensitivity check index: A simple, accurate method for assessing insulin sensitivity in humans. J. Clin. Endocrinol. Metab., 85(7): 2402-2410.

Kim, B Y; Jung, C H; Mok, J O; Kang, S K and Kim, C H (2012). Association between serum C-peptide levels and chronic microvascular complications in Korean type 2 diabetic patients. Acta Diabetol., 49(1): 9-15.

Kritchevsky, D (2000). Overview: Dietary fat and atherosclerosis. Asia Pac. J. Clin. Nutr., 9(2): 141-145.

Lipp, M and Anklam, E (1998). Review of cocoa butter and alternative fats for use in chocolate Part A. Compositional data. Food Chemistry, 62(1): 73-97.

Lopez-Miranda, J and Marin, C (2010). Dietary, physiological, and genetic impacts on postprandial lipid metabolism. Fat detection: taste, texture, and post ingestive effects. CRC Press/Taylor and Francis.

Lopez, S; Bermudez, B; Ortega, A; Varela, L M; Pacheco, YM; Villar, J; Abia, R and Muriana, FJ(2011). Effects of meals rich in either monounsaturated or saturated fat on lipid concentrations and on insulin secretion and action in subjects with high fasting triglyceride concentrations. Am. J. Clin. Nutr., 93(3): 494-499.

Matthews, D R; Hosker, J P; Rudenski, A S; Naylor, B A; Treacher, D F and Turner, R C (1985). Homeostasis model assessment: Insulin resistance and beta-cell function from fasting plasma glucose and insulin concentrations in man. Diabetologia, 28(7): 412-419.

Mensink, R P; Zock, P L; Kester, A D and Katan, M B (2003). Effects of dietary fatty acids and carbohydrates on the ratio of serum total to HDL cholesterol and on serum lipids and apolipoproteins: A meta-analysis of 60 controlled trials. Am. J. Clin. Nutr., 77(5): 1146-1155.

MPOB (2004). MPOB Test Method. MPOB, Bangi.

Nimptsch, K; Brand-Miller, J C; Franz, M; Sampson, L; Willett, W C and Giovannucci, E (2011). Dietary insulin index and insulin load in relation to biomarkers of glycemic control, plasma lipids, and inflammation markers. Am. J. Clin. Nutr., 94(1): 182190.

Ortega, A; Varela, L M; Bermudez, B; Lopez, S; Abia, R and Muriana, F J (2012). Dietary fatty acids linking postprandial metabolic response and chronic diseases. Food Funct, 3(1): 22-27.

Salas, J J; Bootello, M A; Martinez-Force, E and Garces, R (2009). Tropical vegetable fats and butters: Properties and new alternatives. OCL, 16(4): 254258.

Sanders, T A and Berry, S E (2005). Influence of stearic acid on postprandial lipemia and hemostatic function. Lipids, 40(12): 1221-1227.

Sanders, T A; De Grassi, T; Miller, G J and Morrissey, $\mathrm{J} \mathrm{H}$ (2000). Influence of fatty acid chain length and cis/trans isomerization on postprandial lipemia and factor VII in healthy subjects (postprandial lipids and factor VII). Atherosclerosis, 149(2): 413420.

Storlien, L H; Jenkins, A B; Chisholm, D J; Pascoe, W S; Khouri, S and Kraegen, E W (1991). Influence of dietary fat composition on development of insulin resistance in rats. Relationship to muscle 
triglyceride and omega-3 fatty acids in muscle phospholipid. Diabetes, 40(2): 280-289.

Storlien, L H; Pan, D A; Kriketos, A D and Baur, L A (1993). High fat diet-induced insulin resistance. Lessons and implications from animal studies. Ann. N Y Acad. Sci., 683: 82-90.

Teng, K T; Nagapan, G; Cheng, HM and Nesaretnam, K (2011). Palm olein and olive oil cause a higher increase in postprandial lipemia compared with lard but had no effect on plasma glucose, insulin and adipocytokines. Lipids, 46(4): 381-388.

Tholstrup, T and Samman, S (2004). Postprandial lipoprotein(a) is affected differently by specific individual dietary fatty acids in healthy young men. J. Nutr., 134(10): 2550-2555.

Tholstrup, T; Sandstrom, B; Bysted, A and Holmer, G (2001). Effect of 6 dietary fatty acids on the postprandial lipid profile, plasma fatty acids, lipoprotein lipase and cholesterol ester transfer activities in healthy young men. Am. J. Clin. Nutr., 73(2): 198-208.

Zampelas, A; Williams, C M; Morgan, L M; Wright, J and Quinlan, P T (1994). The effect of triacylglycerol fatty acid positional distribution on postprandial plasma metabolite and hormone responses in normal adult men. Br. J. Nutr., 71(3): 401-410. 